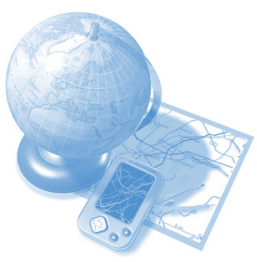

\author{
Douglas Halliday \\ Physics Department \\ Durham University \\ South Road \\ Durham DH1 3LE \\ d.p.halliday@ \\ durham.ac.uk
}

\section{Enterprise Skills for Physics Undergraduates}

\begin{abstract}
With the support provided by a Physical Sciences Centre Development Project we have developed a self-contained 3-hour seminar activity that explores entrepreneurship and creativity. The seminar is aimed at first year undergraduate physicists. The seminar introduces the concepts of entrepreneurship, has some short warm-up activities and is followed by the main business game. Teams are required to give a presentation of their outcomes at the end. All participants vote on the best proposal. Resources including PowerPoint files and handouts are included in the project resource pack.
\end{abstract}

\section{Background}

There are a number of drivers for the inclusion of skills development within undergraduate and postgraduate degree programmes. The Dearing report of the National Committee on Inquiry into Higher Education (1997) contained recommendations on employability and work experience, and encouraging entrepreneurship in HE programmes. More recently the Roberts' Report 'SET for Success - The Supply of People with Science, Technology, Engineering and Maths Skills' (2002) contained recommendations that; "... the training elements of a PhD - particularly training in transferable skills - need to be strengthened considerably". Furthermore that; "HEFCE and the Research Councils ... should make all funding related to PhD students conditional on students' training meeting stringent minimum standards". It continued: "In particular, the Review believes that HEls must encourage PhD projects that test or develop the creativity prized by employers."

Employment is becoming an increasingly important concern for most students. It is known that a student's capability for continued life-long learning is determined largely through University experience. The widening participation agenda has introduced a greater need for skills development in undergraduate programmes. Increasing undergraduate populations have resulted in more competitive recruitment processes with the need for students to make their acquired skills more explicit. Employment statistics reveal that a significant proportion of undergraduates choose a career not related to their subject of study and that $60 \%$ of graduates leave their first job in 3 years. Employability is now a central theme of the DfES (The Department for Education and Skills) strategy. The government wishes to see an increase in the skills base in the UK. In the European context the European Union has set itself the goal of becoming the most competitive and dynamic knowledge-based economy in the world by 2010 - the 'Lisbon Strategy'.

The issues of broader skills and employability are challenging traditional views of higher education and its role. There is a growing recognition that, in addition to providing a thorough and rigorous grounding in an academic discipline, universities should also be considering how they equip students with a range of skills to prepare them as life-long learners who will take responsibility for their continued professional development beyond their university education. We now have skills included in level descriptors in the National Qualifications Framework, QAA (Quality Assurance Agency) subject benchmark statements and the QAA Code of practice: Career, Education, Information and Guidance.

A look at developments of the last 10 years shows a decline in large corporate research activity. This has had a significant impact on research overall in the UK with a decline in science and engineering research base. We have seen a substantial increase in spin-off firms created by professional scientists. For many of these the long term success is not guaranteed. Graduates in general are ill-equipped for this type of career path. 
To be successful it is accepted that 'skills' should be embedded in academic programmes rather than a bolt on. The students' perception is that they then have the same importance (and assessment weighting!) as more traditional academic work. Effective skills training encourages students towards strategic thinking and reflection, and for many students developing skills requires recognition of how they learn. This process can be reinforced by formative assessment and feedback which have an important role in skills development. Good formative feedback can stimulate a reflective approach to learning and encourage continuous selfassessment of work. There is a growing body of evidence that skills make students better learners. Addressing skills through the curriculum can have a positive impact on the academic and long-term performance of students. In particular skills encourage reflection and articulation, both key elements of successful recruitment.

\section{What are Enterprise Skills?}

One definition is: "entrepreneurship is the innovatory process involved in the creation of an economic enterprise based on a new product or service which differs significantly from products or services in the way its production is organised, or in its marketing." (Curran and Burrows ${ }^{3}$ ). An alternative definition is: "person in effective control of commercial undertaking; one who undertakes a business or enterprise, with a chance of profit or loss; contractor acting as an intermediary." (Oxford Dictionary).

It is interesting to consider the type of entrepreneurial and

\begin{tabular}{|l|l|}
\hline Bureaucratic/Corporate & Entrepreneurial \\
\hline Order & Untidy \\
Formality & Informal \\
Information & Observing \\
Planning & Intuitive \\
Corporate Strategy & Tactics \\
Control Measures & Individuality \\
Formal Standards & Personally observed \\
Transparency & Ambiguous \\
Functional Expertise & Holistic \\
Systems & Free environment \\
Performance appraisal & Customer focus \\
Positional authority & Shared tasks \\
\hline \multicolumn{2}{|c|}{ Table 1: A comparison of the entrepreneurial setting } \\
\multicolumn{2}{|c|}{ with the corporate setting. } \\
\hline
\end{tabular}

creative activity that we are trying to develop in our students and compare that with the way in which most of our institutions are managed.

In terms of pedagogic process the outcomes we are seeking are in three broad categories: 1) behaviours (independent, achieving, flexibility, persuasive, commitment); 2) skills (problem solving, creativity, planning, negotiating, decision maker); 3) attributes (confident, autonomous, versatile, dynamic, resourceful).

The challenge for Physics departments is to prepare the next generation of scientists, some of whom will require the kinds of qualities discussed above. The need is for a proportion of our graduates to be equipped to realise their full potential in the entrepreneurial age. This has been part of the rationale behind the 13 Science Enterprise Centres set up across the country.
In an article in Physics World ${ }^{13}$, David Auckland the director of the Manchester Science Enterprise Centre writes: "The success of the world's traditional economic powerhouses Europe, US, Japan - for many years depended on their ability to convert basic raw materials into saleable goods. But as developing nations have learned how to produce high-quality artefacts at competitive prices, the role of manufacturing has declined. Knowledge is the raw material of the modern age and success is determined by how fast it can be converted into new added-value products and services".

In this context we decided at Durham that it would be beneficial to introduce first year undergraduate Physics students to an activity designed to stimulate entrepreneurial thinking.

\section{The Seminar}

We developed a 3-hour enterprise skills seminar which includes a 'business game' to stimulate students'

entrepreneurial thinking. The seminar was run as a pilot in the academic year 2003/2004 with a small group of first year undergraduates. The seminar was targeted at first year undergraduate physicists with the aim of making them aware of their own enterprise and creative skills. The seminar emphasised the relevance of these skills to the students by presenting case studies based on members of the Department of Physics in Durham.

One of the intended outcomes is that the students recognise the value of entrepreneurial skills in a wider context, and how these may enhance their effectiveness. It also encourages students to engage efficiently with a particular problem or situation in an area where they have no previous experience. This seminar has been specifically designed to be transferable to other contexts.

Feedback from the pilot group of students was extremely positive and through this a number of areas were identified for development. Students particularly liked the topics for group discussion, which highlighted a number of possible careers involving physics.

Building on the work of the pilot, we have developed a revised 3-hour seminar. The resources for this seminar are available as PowerPoint files.

The Durham Physics enterprise seminar is structured as follows:

1. A self-contained 3-hour seminar, which can be delivered by a member of academic staff to groups of first year undergraduate students. The nature of the seminar and the resource pack ensures that those delivering the seminar do not require specialist entrepreneurial knowledge. This was repeated for the entire class of 200 students. The seminar was incorporated as an element of our first year 'Discovery Skills in Physics' module. The module is designed primarily for students studying Physics or Natural Science programmes. The module aims are:

- to provide basic experimental and key skills required by physicists;

- to provide a structured introduction to laboratory skills development, with particular emphasis on measurement uncertainty and written communication skills; 
- to provide students with practice in the application of mathematics to practical problems.

The entrepreneurial seminar was one of a range of activities undertaken by the students during the course of this module. The seminar is not summatively assessed although formative feedback is given.

1. The first 30 minutes of the seminar give an introduction to the concepts of entrepreneurship. The aim is to show that most people behave in an entrepreneurial, or creative, manner without consciously realising it. The students are encouraged to reflect on traits such as creativity, adaptability and broader thinking, which are important in all walks of life. This may also give students possible ideas for the options available to them as physicists at the end of their degree programme. Our introduction includes examples of familiar names: Henry Ford, Richard Branson, Bill Gates, Steve Jobs and Anita Roddick. Others could be included as appropriate. This section concludes with a brief review of successful businesses which have been set up by staff in our own department.

2. The next stage of the seminar presents two short warm-up activities for the teams (4-6 students). Students are given five minutes to come up with a solution to the two questions:
Feedback has shown that the majority of students engage well with the seminar and are stimulated to consider further their skills in a broader context.
- $\quad$ Prof. $X$ is annoyed because Durham Cathedral is blocking the view from the office. Your task is to think of as many ways as possible to solve Prof. X's problem.

- You need to raise a billion pounds by noon tomorrow. How are you going to do this?

Each team must present their top 5 solutions and everyone votes for their favourite solution.

3. The next two hours of the seminar are activity based. Students, in teams of 4-6, are provided with a pack containing a profile of 'Fermiville'. The pack contains details of demographics, retail outlets and amenities, education, transport and access, local industry, utility infrastructure, cost of living, average salaries and rental properties of this fictional large town. There are proposals for a number of business opportunities. These have a technological flavour to them to reflect physics interest. It would be possible to include other opportunities more pertinent to other subjects. Each venture has a number of positive aspects and a number of flaws (including physical or technological problems). Each group has to choose one of these ventures, which they believe has the potential to succeed and develop a business case for this. The groups are required to devise a short presentation during this period of activity.

4. The final 30 minutes are used for delivering each group's short presentation. The students vote for the best presentation. Time is set aside for open discussion of students' perceptions, and for a questionnaire to be completed.

\section{Feedback}

We have analysed a range of feedback from a sample of student participants. Students were asked to rate 6 aspects of the seminar from 1 (poor) -5 (good):

a. How did you find the seminar overall? (3.6)

b. Was the introduction clear and informative? (4.0)

c. Was the ice-breaker (warm up exercise) useful? (3.6)

d. Was the ice-breaker enjoyable? (4.0)

e. Were the information packs clear and informative? (3.8)

f. Were the business situations described clearly and did they contain enough information? (3.2)

The written comments can be summarised as follows:

1. The majority of students regarded the workshop as highly successful and had a high level of engagement with the tasks they were required to do.

2. Many students commented that they enjoyed this seminar more than other (laboratory-based) aspects of the module.

3. A number commented

favourably about the seminar involving all students.

4. The most useful elements of the seminar were quoted as:

- "Learn what things to think about if you were going to set up a business"

- "More fun than labs"

- "Get some direction on where to go after graduation"

- "Widening your thoughts"

- $\quad$ "The different business ideas show applications of physics degree"

- "The group interaction"

- "The seminar on enterprise was good - a refreshing change"

- "Good to be put in a group and having to work as a team - gave a different perspective. Good to see the more practical aspect of physics"

5. All students who were asked "Would you recommend this to other students?" replied "Yes". 
Staff who had helped deliver the seminar were asked: "How well did students engage with the task?" The responses received were:

1. "I was pleasantly surprised how well the students engaged. I can only think of one or two who did not take it seriously. In particular I think the creative thinking exercises are essential to setting the tone for the session. My strategy was to let students form their own groups of $\sim 4$ at the start of the session."

2. "I left the room for each of the creative thinking exercises and business planning and just let them get on with it. (I did peek round the door occasionally to make sure they were engaged - they always were.)"

3. "Once they had got some way into the process I would then circulate round the groups, helping (or throwing spanners in the works) as appropriate."

4. "One thing that really surprised me was how good and confident the presentations at the end were. Perhaps this is one positive outcome of Curriculum 2000!"

5. "In most instances the other groups seemed to really enjoy questioning the presenting group on their plans."

6. "As part of the debriefing session at the end I normally asked them what they had got out of the session and what we should change. The responses were always positive - much more fun than a normal lab session. I feel that the whole exercise has worked much better than I originally imagined. We definitely should retain this for the future."

\section{Conclusions}

We have developed and successfully piloted a three hour seminar focusing on entrepreneurial skills. Feedback has shown that the majority of students engage well with the seminar and are stimulated to consider further their skills in a broader context. The next stage for Durham is to investigate the possibility of developing an entrepreneurial module.

The concept of this seminar has been shown to work successfully with Physics undergraduates at Durham. A package of materials has been designed which is suitable for delivery by a non-specialist member of staff. The material can be easily adapted for use within other disciplines.

\section{References}

A bibliography is offered as a starting point for further reading

1. Bhave, M. P., A process model of entrepreneurial venture creation, Journal of Business Venturing 9, 223-242 (1994)

2. Bird, B., Demographic approaches to entrepreneurship, Advances in Entrepreneurship, Firm Emergence, and Growth 1, 11-48 (1993)

3. Curran, J. and Burrows, R., The sociology of petit capitalism: A trend report, Sociology - The journal of the British sociological association 20, 265-269 (1986)

4. Curran, J. and Burrows, R., Enterprise in Britain: A National Profile of Small Business Owners and the SelfEmployed, Small Business Research Trust (1988)

5. Domar, E., The entrepreneur: Discussion, American Economic Review 58, 93-94 (1968)

6. Gartner, W. B., What are we talking about when we talk about entrepreneurship? Journal of Business Venturing 5, 15-28 (1990)

7. Gartner, W. B., Who is an Entrepreneur? - is the Wrong Question, Entrepreneurship Theory and Practice 13, 4768 (1989)
8. Hornaday, J. A. and Aboud, J., Characteristics of successful entrepreneurs, Personnel Psychology 24, 141$153(1971)$

9. Jeremy, D., Anatomy of the British business elite, 18601980, Business History 26, 3-23 (1984)

10. Lamont, L. M., What entrepreneurs learn from experience, Entrepreneurship and Venture Management, Raumback, Clifford M. and Mancuso, Joseph R. ,eds., Englewood Cliffs, NJ: Prentice-Hall (1975)

11. Reitan, B., Where Do We Learn That Entrepreneurship is Feasible, Desirable and/or Profitable?, USASBE Annual National Conference, Entrepreneurship: The Engine of Global Economic Development San Francisco, California (1997)

12. Higher Education Academy Physical Sciences Centre, Employability Briefing Paper

13. Auckland, D., Students take the business test, Physics World 17, (8) $44-45$ (2004)

14. The National Committee of Inquiry into Higher Education, Sir Ron Dearing, (1997) http://www.leeds.ac.uk/educol/ncihe/

15. SET for Success Final Report of Sir Gareth Roberts' Review, Sir Gareth Roberts, (2002) http://www.hm-treasury.gov.uk/Roberts

16. The Code of practice for the assurance of academic quality and standards in higher education, section 8 Career education, information and guidance - http:// www.qaa.ac.uk/academicinfrastructure/codeOfPractice/ default.asp

17. Honours degree benchmark statements for Physics and Astronomy http://www.qaa.ac.uk/academicinfrastructure/ benchmark/honours/physics.pdf

\section{Acknowledgements}

Staff who have contributed to this project are: Dr Lowry McComb, Dr Ifan Hughes, Dr Paula Chadwick, Dr Marek Szablewski and Dr Joy McKenny. We also wish to acknowledge the North East Centre for Scientific Enterprise for funding the initial pilot project on which this work is based. 